\title{
An analysis of factors affecting staffs knowledge sharing in the central library of the University of Isfahan using the extension of Theory of Reasoned
}

\section{Action}

\author{
Sayyed Mohsen Allameh \\ Department of Management, University of Isfahan, Hezarjerib Street, Isfahan, Iran \\ E-Mail: dr_allameh@yahoo.com
}

Ahmad Abedini

Department of Management, University of Isfahan, Hezarjerib Street, Isfahan, Iran

E-Mail: fabedini5@yahoo.com

Javad Khazaei Pool (Corresponding author)

Department of Management, University of Isfahan, Hezarjerib Street, Isfahan, Iran

E-Mail: khazaei110@gmail.com

\begin{abstract}
Ali Kazemi
MS Graduate of University of najaf abad, Isfahan, Iran E-Mail: en_alikazemi975@yahoo.com
\end{abstract}

Accepted: January 24, 2012 Published: March 17, 2012

Doi:10.5296/ijhrs.v2i1.1310 URL: http://dx.doi.org/10.5296/ijhrs.v2i1.1310

\begin{abstract}
The vital importance of knowledge management, in today's complicated and changing environment as a source for strategic reconstruction of an organization cannot be denied. Furthermore, the effective sharing of knowledge is one of the most important success factors
\end{abstract}


in an organization. This study aims at predicting the staff's sharing of knowledge in the central library of the University of Isfahan. The conceptual framework for this study is consisted of the completed model of Theory of Reasoned Action. The statistical population of the current study contains the staffs of central library in university of Isfahan out of which 160 participants were studied by the census method. For the validity evaluation of the model, the structural equations model was applied and based on the results of path analysis relationship between research variables it was confirmed. The research results show that the expected organizational reward, reciprocal benefits, self-efficacy of knowledge, and enjoyment in helping others affect attitude and intention for the sharing of knowledge. The research findings indicate the positive impact of subjective norms on knowledge sharing intentions.

Keywords: Theory of Reasoned Action, Intrinsic motivations, Extrinsic motivations, Subjective norms

\section{Introduction}

Many studies have emphasized on knowledge management as an important factor to maintaining organizational competitive advantage. (Holsapple,2005). The knowledge management programs shouldn't be considered to be separated from other organizational programs. In knowledge management, culture and motivational processes are among the most important success factors. In other words, knowledge management would not achieve its goals without human resources management (Scarbrough and Kinnie,2003).Knowledge in the age of information technology is one of the main resources of accessing to the advantage of competition in a dynamic and competitive environment (Brent and Vittal 2007; Wang and Noe 2010). Organizations should seek specialists and experienced forces or teach them the needed abilities to achieve competition advantage. But these actions are not enough and it's needed to take the transmission of experience and knowledge from experts to amateurs into consideration (Hinds et al. 2008). Accordingly it's favorable that organizations have more emphasis on the existing knowledge-oriented sources (Yang Chen,2009). The sharing of knowledge is a basic means to apply knowledge, establish innovation and utilize that in the organization and finally get access to Competitive advantage (Jackson, 2006). The sharing of knowledge among people provides us with profitability and investment on knowledge oriented resources (Cabrera and Cabrera, 2005). Many attempts to design comprehensive systems of knowledge management have led to failure because they have not support the beliefs of their staffs. Control and force in knowledge sharing is an impossible job. Companies should try to get access to more strategic methods in order to encourage the staffs to share knowledge with their colleagues. Based on expectation theory, more positive results in a work will be gained when people show more interest in that job. From the perspective of behavioral investigations, extrinsic motivations (rewards) have found to be significantly effective on staffs' cooperation.( Fenwick and Olson, 1986). Therefore, certain kinds of extrinsic motivations, financial rewards, or encouragement and complimenting in public may provoke knowledge sharing. In addition, review of literature shows that the increase of intrinsic motivations, has correlation with 
staff's tendency to provide a positive environment and consequently increase learning and tendency for voluntary cooperation in knowledge sharing(Osterloh and Frey, 2000). Although many studies have discussed the fact that provoked motivations are the important determinants of knowledge sharing behaviors, there are not significant experimental studies which investigate the effects of difference between provoked intrinsic and extrinsic motivations of knowledge sharing behaviors. In the Theory of Reasoned Action (TRA), Fishbein and Ajzen claim that people's personal views and beliefs explain most human behaviors. The Theory of Reasoned Action is useful in predicting a wide range of behaviors and has been used extensively to predict and explain behavioral intention and real behavior in social psychology (Chang, 1998; Slocombe,1999; Njite and Parsa,2005). However, previous studies have proved the need to include other components in order to provide a broader perspective and better explanations regarding human behaviors (Liker and Sindi, 1997).Specifically, the factors related to human and social changes processes should be established as the Theory of Reasoned Action. Accordingly with combining the motivational view and the Theory of Reasoned Action, this study will investigate the role of both intrinsic and extrinsic motivations in describing the staffs' intention in knowledge sharing. The model for this research and respective hypotheses has been tested experimentally using the method of structural equation model. To this end, the Amos 18 software has been used to perform the test. In addition, the findings of current research provide theoretical and experimental foundations for probable orders to predict and explain the staffs' knowledge sharing. The findings of this research are hoped to enable the heads of financial institutions or decision makers to appropriately formulate methods and organize the job to ensure establishing an effective knowledge sharing culture.

\section{Literature Review}

\subsection{Knowledge and knowledge management}

Knowledge: explaining the knowledge in brief is not much easy. In the literature of knowledge management the difference between data information, and knowledge is mentioned in the writings; although these three terms are usually used interchangeably in the writings, the data can be regarded as raw facts, while information is the raw data which is categorized, structured and organized. Knowledge is the information which is increased in value by giving meaning and significance and also is filtered by people's minds (Grover and Davenport, 2001).knowledge can be regarded as a meaningful and precious concept. When data, information and knowledge are posed on a continuum, knowledge has the highest value and it is mostly related to decision making and operations and engages most of the people. Knowledge is usually divided into two categories of tacit and explicit. Tacit knowledge is in one's thought and it can hardly be expressed, codified and recorded. In contrast, the explicit knowledge can be expressed, codified and formulated physically and electronically. The real value of organizations depends on the knowledge and ideas inherent in peoples' attitudes.( Bollinger and Smith ,2001). The organizational knowledge due to having four vital characteristics of 
preciousness, uniqueness, inimitability and irreplaceability is regarded as a strategic wealth(Meso and Smith 2000). nonstrategic wealth or in other words concrete resources cannot persist as a competitive superiority and bring success for the organization in the long run.Knowledge management: knowledge management has been considered as an organized process to create, achieve, distribute, use the leverage feature of knowledge to support the competitive superiority and achieve organizational aims. An important issue in knowledge management is the gap between theory and fact. Universities have conducted complicated and advanced projects studying different advantages and experiences of the application of knowledge management without understanding all of its ambiguities. Few studies have established a strong relation between knowledge management and value improvement process. Most articles focus on the existence of knowledge, the relationship between knowledge and its features and decision making. Knowledge management is usually regarded as a multidimensional and interdisciplinary subject which sometimes disperse discussions on this topic. Gupta, et.al (2000) said that $\mathrm{KM}$ is a procedure which helps organizations in finding, selecting, planning, distributing and conveying important information and specialties needed for activities such as problem solving, active learning, strategic planning and decision making. Libowitz (2001), regards the recording, sharing, applying and establishing of knowledge in organizations as the best power to penetrate internal and external resources. However, $\mathrm{KM}$ has been expressed as an active and formulated approach to manage and optimize knowledge resources in an organization. In general, lots of methods to utilize KM exist and there are different approaches and dimensions suitable for a certain organization. Dimensions consist of finance, production, and providing services, organizational culture, the bigness of institution, resources access and etc. which as determining factors determine how KM should be used. In common approach to KM, the information technology is used to simplify, collect, store, apply and unify the knowledge. The construction of KM system is consisted of data base, searching and marketing engine, group tools or even a common mental system. In other words, some organizations emphasize spreading the knowledge sharing culture, organizational learning, encouraging group work or managing human resources in order to access KM. in an attempt to spreading the understanding of KM approach, Hansen et al (1999) introduce two methods of codification and personalization which organizations select. based on this approach knowledge is extracted from people then it's codified, recorded and stored in knowledge resources to be available and restored for future use. This method is a way to receive knowledge from people who are specialized in that, so it will remain in the organization. In contrast, the personalization theory concentrates on knowledge which is shared through contact, communication and a person's conversation with another person. Knowledge remains in people's minds and interactions and with its extraction KM would be accessed. In order to develop a strong and stable knowledge management system, it would be better to pay special attention to the key topics mentioned below.

1. How to organize and structure a knowledge information source.

2. The best mechanism to convey knowledge from the clerks to each other and from the system to the clerks and vice versa. 
3. Maintenance and protection of the KM system.

4. Producing a KM system which lets easier use and communication.( Awazua and Desouza, 2004).

\subsection{Knowledge sharing}

Knowledge sharing consists of a set of behaviors containing knowledge and information exchange and helping others in this respect. Knowledge sharing, resembles organizational citizen behaviors which are done voluntarily and optionally in organizations. One of the methods of measuring knowledge management, by the amount of knowledge sharing includes explicit and tacit knowledge which is used in organizations. Yahya and Goh (2002), found that sharing and distributing the knowledge is positively correlated with knowledge management. Unofficial sharing of knowledge in organizations can be very effective for example the staffs of the 3-M company share knowledge by telling stories(Schilligo, 2007). Knowledge sharing happens when an individual tends to get help and learn from others to develop new competences. The final goal of knowledge sharing among staffs, is trying to convey the knowledge and experiences of people and keep them as organizational resources and wealth in order to increase and materialize the organizational effectiveness. Salopek (2009) says: if we want the people in an organization to share what they learn we should provide conditions in which sharing would be a result of personal superiority. Motivational programs include internal, external and social rewards which should be established and developed. These programs and rewards increase knowledge creation, sharing, conveying and utilizing. Staffs should simultaneously learn the fact that rewards are not just for knowledge sharing. Staffs not only should keep their knowledge after sharing but also they should receive an input related to the shared knowledge from other groups or persons. In addition to educational programs, mentoring programs should also be used. These programs apply the knowledge and experience of people to convey their learning. This exchange reinforces the knowledge and creates knew knowledge(Yang and Wan, 2004).

\subsection{Theory of Reasoned Action}

This theory was developed by Fishben and Ajzen in the book of " belief, attitude, intention and behavior: "an introduction to theory and research" and it's based on this hypothesis that people act rationally. They accumulate all available information about goal behavior and evaluate it exactly. Furthermore, they take the effect and result of actions into consideration , then they decide based on their reasoning to do or not to do an action (Pikkarainen et al,2004). Figure 1, shows this theory: 


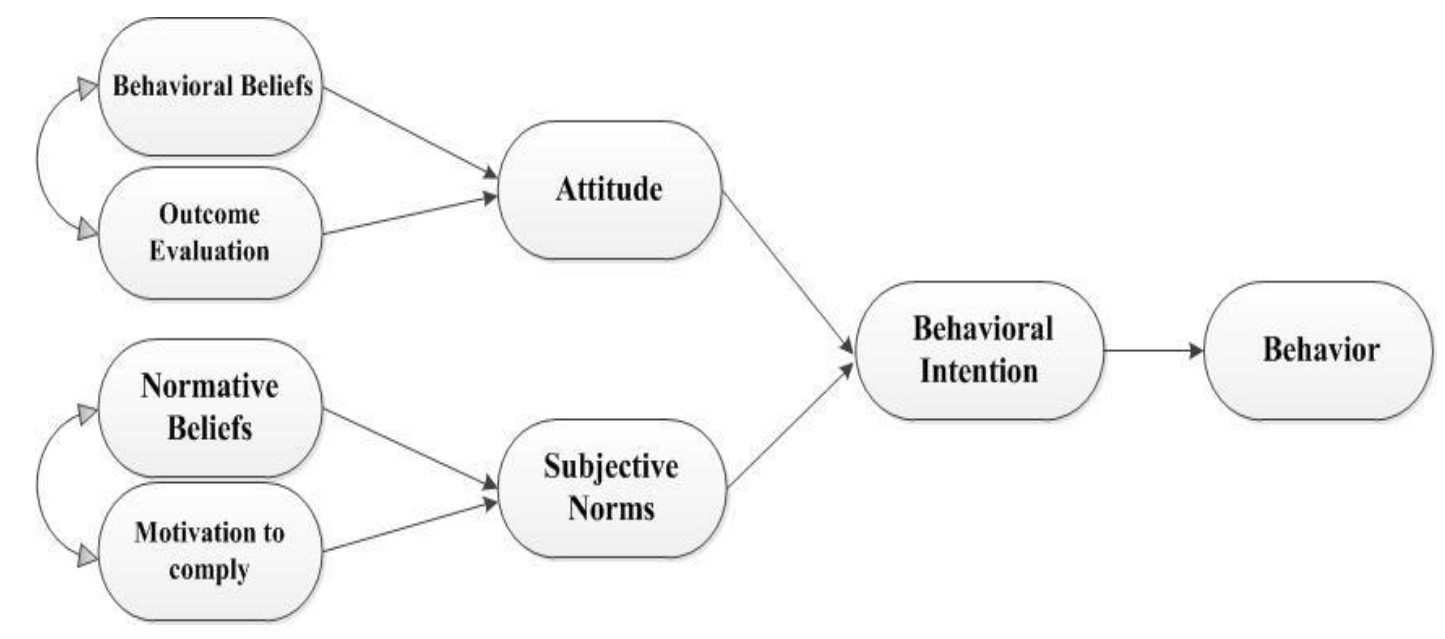

Figure1, The Theory of Reasoned Action (Vallerand et al, 1992).

In this theory, the subjective norm points to the social pressure perceived by the individual to do or not to do the goal behavior. People, usually act based on their perception of what others(friends, family, colleagues,...) think should do and their intention to accept a behavior is potentially affected by those who have close relationships with them (Mathieson,1991). In Theory Reason Action, the individual's subjective norm, is the result of interaction between normative beliefs ( expectations perceived by persons or special reference groups) and personal motivation to do the goal behavior regarding these expectations (Davis et al, 1989).Attitude is defined as a positive or negative feeling about showing the goal behavior. The individual's personal attitude toward the behavior is the result of combination of attitudinal beliefs ( the person's mental possibility that the goal behavior would lead to i result) and evaluation of those consequences( evaluative response, clear regarding the result. (Fishbein.and Ajzen, 1975).Behavioral intention indicates the intensity of personal intention and will to do the goal behavior (Morris and Dillon, 1997). The relationship between behavioral intention and behavior shows that people intend to involve in behaviors for which they have intention therefore behavior always follows behavioral intention and is connected to it.In the Theory Reason Action, it's claimed that behavior is only controlled by behavioral intention therefore this theory is limited to voluntary behaviors( behaviors which only need the person's will and intention to be done). However behavior needs abilities, resources and opportunities which are not easily and cheaply accessible but This case is not regarded in the domain of practical capabilities of the Theory Reason Action or possibly it wouldn't be predicted by this theory completely(Conner and Armitage,1998). The Theory Reason Action has been widely applied in studies related to the acceptance of different information technologies(Karahanna et al,1999).

\subsection{Extrinsic and intrinsic motivation}

Two sets of motivations are intrinsic and extrinsic motivations which are defined and tested in different texts and studies (Vallerand,2000). Extrinsic motivation focuses on goal-oriented reasons, for example, getting rewards and advantages in return for an activity a person does, while intrinsic motivation refers to the inner joy and satisfaction in a person which is gained by doing a special activity. Both of them affect personal intentions and real behaviors of 
people in relation to a specific behavior (Moon and Kim, 2001). The extrinsic motivation of an employee for knowledge sharing, is resulted by the belief that is mostly based on his perception of the association value, while the association is created by exchange.( Osterloh and Frey, 2000).For instance, staffs get committed to knowledge exchange based on the analysis of cost-benefit. Staffs compare the rewards expected from knowledge exchange with its costs. From the socio-economic standpoint, if the observed advantages, are more or equal to the knowledge exchange costs, the process of exchange would go on otherwise the process would stop. Regarding the case of knowledge sharing , costs include factors related to staffs' efforts. ( for example, the spent time, mental effort and etc.) while the potential profits include the received organizational rewards or obligations arranged to compensate for the efforts of those staffs who share knowledge(Ko et al , 2005). Therefore, this study contains the expected organizational rewards and reciprocal advantages which are regarded as the important determinants of the staffs' extrinsic motivations for knowledge sharing behaviors. The intrinsic motivation points to the attractiveness of an activity which based on personal reasons and without any profits seeks joy and satisfaction resulted by the experience. For example in knowledge sharing, staffs are satisfied by enjoying their knowledge self-efficacy or getting assured of the usefulness of their knowledge for the organization (Constant et al, 1996). Previous studies have proved the important role of intrinsic motivations in explaining human behaviors in different situations such as knowledge sharing(Vallerand, 2000). Several studies, also, have applied qualitative or conceptual approaches to understand the intrinsic and extrinsic motivations which are the basics of knowledge sharing behavior(Osterloh and Frey, 2000). However Tylerand Blader(2001) said that intrinsic motivations are important determining factors for knowledge sharing behaviors in individuals.

\section{The research model and hypotheses}

Figure2 shows the research model. The dependent variable of " intention for knowledge sharing" is selected to be the main variable in the model. The model for this study is an extension of the Theory Reason Action. In the recommended model, the rest of key variables such as intrinsic and extrinsic motivations are added to the model of Theory Reason Action. The inclusion of these variables in the model has changed that to a unified model. The research model and hypotheses are discusses below. 


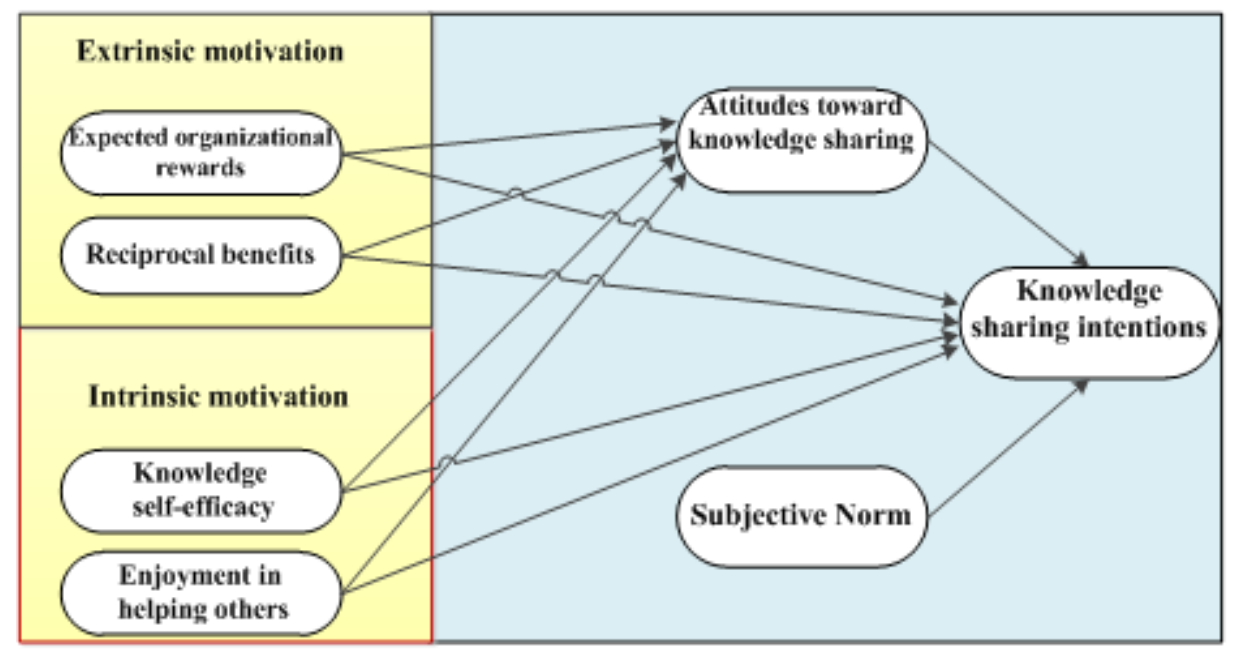

Figure2: the research conceptual model

\subsection{Attitude toward knowledge sharing}

In the Theory Reason Action, attitudes are important predictors of organizational behavior intention. For instance Chang(1998) argues that attitudes affect behavioral intention meaningfully. Bock et al (2005) studied the positive effects of attitudes on people' intentions to share knowledge. In this study, attitudes toward knowledge sharing are referred back to positive or negative evaluation of the knowledge sharing behavior by staffs. Based on the Theory Reason Action and aforementioned issues regarding the staffs' attitude toward knowledge sharing behavior and behavioral intention, the following hypotheses were formulated:

H1. The staffs' attitudes toward knowledge sharing influence the knowledge sharing intentions positively.

\subsection{Subjective norms}

Subjective norms are also critical in knowledge sharing. The positive organizational atmosphere affects the formation of subjective norms and consequently affects the individual's intention to share knowledge (Bock et al., 2005).De Long and Fahey (2000) in a study of the application of knowledge management in 50 companies, found that the negative organizational atmosphere is a serious barrier in organizational knowledge innovations. Based on this the second hypothesis is formulated:

$\mathrm{H} 2$ : an organization with stronger perceived subjective regarding knowledge sharing activities, has a positive effect on the staffs' tendency to share knowledge.

\subsection{Extrinsic motivation}

From the perspective of extrinsic motivation, a person's behavior is provoked by values and the perceived benefits resulted by an act. The fundamental goals in extrinsic motivations, is to achieve organizational rewards or reciprocal benefits (Vallerand,2000). Organizational rewards are useful for encouraging people to do the expected behaviors. Organizational rewards can be put into categorize ranging from financial rewards including raise in salary and benefits to nonfinancial rewards such as promotion and job safety (Hargadon,1998). Organizations introduce reward systems to encourage their staffs to share their knowledge with other members. For example, Lotus development, a part of IBM, has arranged \%25 of 
the total operation evaluation of its backup staffs based on the rate of knowledge sharing activities(Bartol and Srivastava,2002). In this study it's assumed that if the staffs believe that they can get organizational rewards for knowledge sharing, they would have more positive attitudes toward knowledge sharing and therefore this would affect their knowledge sharing intentions. Hence the following hypotheses are suggested:

H3. The expected organizational rewards have positive effects on staffs' attitude toward knowledge sharing.

H4. The expected organizational rewards have positive effects on the staffs' knowledge sharing intention.

In general, an exchange relationship can be consisted of economic resources ( such as money, product, services) and socio-emotional resources ( such as status, devotion and trust). The reciprocity behavior is regarded as one of the benefits of engaging people in social exchange. The reciprocity behavior creates a mutual owing sense, also it makes the people engaging in knowledge sharing to have a general expectation to get help from others. Previous studies show that knowledge sharing occurs in online committees by the strong sense of reciprocity (Wasko and Faraj,2005). furthermore, researchers observed that reciprocal benefits can be effective motivations to ease knowledge sharing, hence individuals would be led to a long term cooperation (Bock et al,2005). So, if staffs believe that they can get reciprocal benefits by sharing their knowledge with other staffs, it would be likely for them to have more positive attitudes toward knowledge sharing and intend to do so. Therefore, the following hypotheses were suggested:

H5. Reciprocal benefits positively affect the staff's attitude toward knowledge sharing.

H6. Reciprocal benefits positively affect the staff's knowledge sharing intention.

\subsection{Intrinsic motivation}

From the perspective of intrinsic motivation, the behavior is evoked by the staffs' need of competence and self-efficacy facing their environment. Competence or self- efficacy is defined as peoples' judgment about their abilities to organize and administrate the operation phases needed to get to a certain level of performance. Competence or self-efficacy can help staffs with their motivation for knowledge sharing with colleagues (Kankanhalli et al,2005). Researchers found that those staffs who are more confident about their abilities , possibly would provide more valuable knowledge to do specific works. Knowledge self-efficacy in individuals reveals with the belief that their knowledge can help them to solve job problems and improve working (Luthans, 2003). The staffs who believe that they can help the organization's performance by sharing their knowledge, have a more positive attitude and stronger intention to share knowledge, therefore the following hypotheses were formulated:

H7. The self-efficacy of knowledge, influence the attitude of staffs toward knowledge sharing positively.

H8. The self-efficacy of knowledge, affect the staffs' intention to share knowledge positively.

Enjoyment in helping others is derived from the concept of altruism. Knowledge workers may be provoked by the altruism tendency to help others (Constant et al, 1996). Previous 
studies show that staffs are provoked by intrinsic motivations in cooperation for knowledge because mental searches and problem solving are challenging or pleasant and employees enjoy them. (Wasko and Faraj,2005) . knowledge contributors who enjoy helping others may be more favorably oriented and inclined to share knowledge. Therefore the following hypotheses were formulated:

H9. Enjoyment in helping others influences the staffs' attitude toward knowledge sharing positively.

H10. Enjoyment in helping others influences the staffs' intention for knowledge sharing positively.

\section{Research method:}

Based on the method of data gathering, this study can be regarded as a descriptive research. since the data are accumulated through sampling from the population, to investigate the distribution of the characteristics of the statistical population, this study is considered to be survey which applies a sectional* method.

\subsection{The statistical population and sampling method}

The statistical population of this research was the staffs of central library in University of Isfahan. For sampling from this population the census method was used due to the few number of staffs. Based on this method, 160 questionnaire were distributed out of which 154 ones were collected . three questionnaire were identified to be discredited to go through data analysis. Therefore, in general, 151 questionnaire were used in this study.

\subsection{Data gathering instruments}

The questions related to the evaluation of the studied model structures are compiled and adapted using the five-choice Likert scale which is based on the standard questionnaire used in similar studies (Lin,2007, Kuo and Young, 2008).

\subsection{The validity and reliability of questionnaire}

To ensure validity of questionnaire, the validity content method was used, in a way that the primary questionnaire was reviewed by experts, specialists and scholars in the field of knowledge management and organizational behavior and their opinions about the questions' number, presentation method, primacy and recency and response choices range were regarded. eventually, after several phases of reviewing and a pilot study, the final questionnaire was prepared. In this study, the Cronbach's Alpha method was used to calculate the reliability coefficient. The calculated Cronbach's alpha value for all the variables of this research is $\% 83$ which may indicate the validity and reliability of the questionnaire. The Cronbach's Alpha values for research variables are shown in table1: 
Table1: The Cronbach's Alpha values for variables

\begin{tabular}{|c|c|r|}
\hline Variable Name & Number of items & Cronbach's $\boldsymbol{a}$ \\
\hline $\begin{array}{c}\text { Expected organizational } \\
\text { rewards(EOR) }\end{array}$ & 4 & 0.81 \\
\hline Reciprocal benefits(RB) & 4 & 0.83 \\
\hline $\begin{array}{c}\text { Knowledge } \\
\text { self-efficacy(KSE) }\end{array}$ & 4 & 0.86 \\
\hline $\begin{array}{c}\text { Enjoyment in helping } \\
\text { others(EHO) }\end{array}$ & 4 & 0.87 \\
\hline $\begin{array}{c}\text { Subjective Norm(SN) } \\
\text { Attitude }\end{array}$ & 4 & 0.79 \\
\hline Intention & 4 & 0.88 \\
\hline Total & 27 & 0.83 \\
\hline
\end{tabular}

\section{4. data analysis method}

For the analysis of data, the SPSS 18 and Amos software were used. To test the hypotheses of this study, a test and to investigate the overall fit of research model, the structural equations modeling was applied. In structural equations modeling one hand the degree of concordance between the research data and conceptual model will be investigated to see if it has an appropriate fit and on the other hand the significance of relationships in this fit model will be tested. The appropriate model fit indices include AGFI, GFI, RMSEA, $\mathrm{Cmin} / \mathrm{df}$ in a way that a model would have an acceptable fit in which Cmin is less than 3 in relation to the freedom degree(df), The RMSEA value is less than \%10, the GFI, AGFI, IFI, CFI, NFI, NNFI values are more than $\% 90$ and the PNFI value is bigger than $\% 50$.

\section{Results}

After ensuring the correctness of measuring models through the software, the research hypotheses were tested and the analysis results are included in Figure 3.

To determine the validity of model, a number of validity fit indices were used. These indices were extracted from the Amos 18 software and shown in table 2. 
Table2. The fit indices of the research conceptual model

\begin{tabular}{|c|c|c|c|c|c|c|c|c|c|}
\hline RMSEA & PNFI & IFI & CFI & NFI & NNFI(TLI) & AGFI & GFI & Cmin/df & Indices Name \\
\hline $0 / 008$ & 0.713 & 0.955 & 0.961 & 0.944 & 0.951 & 0.927 & 0.951 & 1.92 & Final model \\
\hline$\%<10$ & $50 \%>$ & $90 \%>$ & $90 \%>$ & $90 \%>$ & $90 \%>$ & $90 \%>$ & $90 \%>$ & $<3$ & Acceptable fit \\
\hline
\end{tabular}

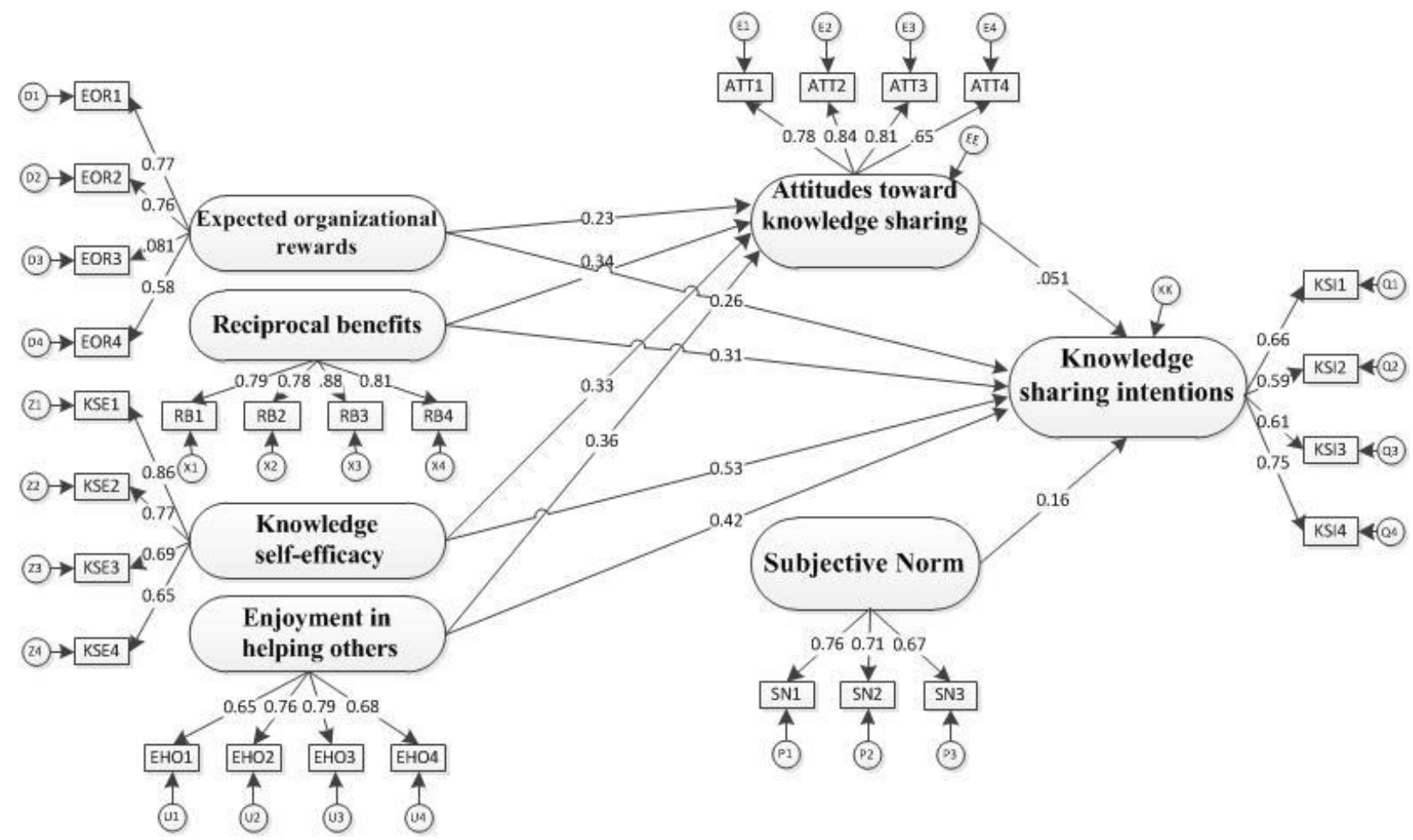

Figure 3. The pattern for the structural equations of the research variables

The data in the above table(Table2) indicate that the research conceptual model has a good fit.

\section{Investigation of relationship between variables}

Since in this study the confidence level is considered as \%95, based on table 3 it's obvious that if the significance numbers in this table are bigger than 1.96 , the related hypothesis with the specified standard coefficient would be confirmed otherwise it wouldn't be confirmed. In table 3, the hypotheses were tested by $\mathrm{t}$ values in an error level of 0.05 . from the ten formulated hypotheses, all the hypotheses were confirmed. 
Table3: obtained results for the structural equations model and test of hypotheses.

\begin{tabular}{|c|c|c|c|c|}
\hline Hypotheses & Path & $\begin{array}{c}\text { Standardized } \\
\text { estimate }\end{array}$ & t-value & Results \\
\hline H1 & Attiude $\longrightarrow$ Intention & 0.51 & 5.93 & Supported \\
\hline $\mathrm{H} 2$ & $\mathrm{SN} \longrightarrow$ Intention & 0.16 & 3.21 & Supported \\
\hline $\mathrm{H} 3$ & EOR $\longrightarrow$ Attiude & 0.23 & 3.82 & Supported \\
\hline $\mathrm{H} 4$ & EOR $\longrightarrow$ Intention & 0.26 & 3.93 & Supported \\
\hline H5 & $\longrightarrow$ Attiude & 0.34 & 4.48 & Supported \\
\hline H6 & $\mathrm{RB} \longrightarrow$ Intention & 0.31 & 4.24 & Supported \\
\hline $\mathrm{H} 7$ & KSE $\longrightarrow$ Attiude & 0.33 & 4.44 & Supported \\
\hline $\mathrm{H} 8$ & KSE $\longrightarrow$ Intention & 0.36 & 5.11 & Supported \\
\hline H9 & $\mathrm{EHO} \longrightarrow$ Attiude & 0.53 & 6.18 & Supported \\
\hline H10 & EHO $\longrightarrow$ Intention & 0.42 & 5.53 & Supported \\
\hline
\end{tabular}

\section{Discussion and Conclusion}

Based on the Theory Reason Action, the staff's attitude and subjective norms, would predict his behavioral intention. The staffs with stronger knowledge sharing intentions have more positive attitudes toward knowledge sharing behavior and the subjective norms, also would support the individual's intention to share knowledge. The findings of this study are in agreement with the findings of other researches concerning knowledge sharing based on the Theory Reason Action.( Lin and Lee, 2004,Chow and Chan,2008; Tohidinia and Mosakhani,2010). Furthermore, it was found that the expected organizational rewards influence the staff's attitude and intention for knowledge sharing significantly. These results are also in concordance with previous studies since the previous research showed that the expected organizational rewards are of great importance in growth of knowledge sharing culture (Kankanhalli et al,2005). The results of this study indicate that reciprocal benefits affect both the people's attitude regarding knowledge sharing and the staff's knowledge sharing intention significantly. The findings of this study are in concordance with the findings of Scott (2000). He argues that the collaboration of staffs highly depends on their confidence about reciprocal benefits and sharing knowledge and information would not happen without cost and reciprocal benefits. the attitude and intention of staffs in relation to knowledge 
sharing are formed by their expectations regarding reciprocal benefits of knowledge sharing. It was also found in this study that the staffs 'attitude toward knowledge sharing and knowledge sharing intention are correlated appropriately with intrinsic motivation. These results implicitly indicate that the staffs' trust and sense of competence may be necessary to make them committed to knowledge sharing. This fact that staffs believe in their abilities acts as a strong motivation to share knowledge with colleagues. Those staffs who have a positive feeling about sharing their knowledge with others would take advantage of this feeling as a strong motivation to share knowledge. Provoking the staffs to share knowledge necessitates understanding the main motivations for knowledge sharing behavior . this study combines the motivational aspect of behavior with the Theory Reason Action and assess the intrinsic and extrinsic motivations as key factors affecting the staff's intention and attitude toward in relation to knowledge sharing. The findings showed that the staffs' attitude toward knowledge sharing are significantly related to the intention to share knowledge. The four aforementioned motivational factors ( the expected organizational rewards, reciprocal benefits, self-efficacy of knowledge, and enjoyment in helping others) are positively related to staffs' intention and attitude regarding knowledge sharing. Based on the obtained data all research hypotheses were confirmed and results are in concordance with previous studies except for some cases. Although the approach of this research is case study, the findings would be helpful for knowledge-based industries and related companies. The modern commercial environment is increasingly unpredictable and the ability of companies to control internal resources and increase knowledge sharing in employees is vital to survive the competitive market. The companies which are able to know the power of knowledge and extend the culture of sharing knowledge can better be prepared to compete in the market. The managers in knowledge-based companies should note that every aspect of value chain can only be efficient by the efficiency of the structure of knowledge sharing. the development of factors which may encourage knowledge sharing and support the attitude which may lead to intentions to share knowledge are among issues which should be regarded by companies. When these elements are posed appropriately in the company, these companies can provoke staffs to actively share knowledge in the workplace.

\section{References}

Awazua ,Y., Desouza, K.C., (2004), The Knowledge Chiefs:: CKOs, CLOs and CPOs, European Management Journal, 22 ( 3), 339-344.

Bartol ,K. Srivastava, A., (2002), Encouraging knowledge sharing: the role of organizational reward systems, Journal of Leadership and Organization Studies, 19(1), 64-76.

Bock, G., Zmud, R., \& Kim, Y. (2005). Behavioral intention formation in knowledge sharing: Examining the roles of extrinsic motivators, social-psychological forces, and organizational climate. MIS Quarterly, 29(1), 87-111.

Bollinger, A. S., Smith, R.D. (2001) Managing organizational knowledge as a strategic asset, Journal of Knowledge Management, , 5 (1),8 - 18.

Brent M. H. and S.A Vittal. (2007), Knowledge sharing in large IT organizations: a case study. The journal of information and knowledge management systems, 37(4), 421-439.

Cabrera, E. F., and A. Cabrera. (2005), Fostering knowledge sharing through people management practices. 
International Journal of Human Resource Management, 16(3), : 720-735.

Chang, M.K., Predicting unethical behavior: a comparison of the theory of reasoned action and the theory of planned behavior, Journal of Business Ethics ,17(6) (1998) 1825-34.

Chow ,W.sS., Chan ,L.S.,(2008), Social network, social trust and shared goals in organizational knowledge sharing, Information \& Management ,45(5), 458-465.

Conner, M., \& Armitage, C.J. (1998). Extending the theory of planned behavior: A review and avenues for further research. Journal of Applied Social Psychology, 28(15), 1429-1464.

Constant, Sproull, D., L. , Kiesler, S., (1996), The kindness of strangers: the usefulness of electronic weak ties for technical advice, Organization Science 7(2), ,119-35.

Kankanhalli, A., Tan ,B.C.Y. and Wei ,K.K., (2005), Understanding seeking from electronic knowledge repositories: an empirical study, Journal of the American Society for Information Science and Technology, 56(11), 1156-66.

Karahanna, E., Straub, D.W.,\& Chervany, N.L. (1999). Information technology adoption across time: A cross-sectional comparison of preadoption and post-adoption beliefs. MIS Quarterly, 23( 2), 183-213.

Davis, F.D., Bagozzi, R.P., \& Warshaw, P.R. (1989). User acceptance of computer technology: A comparison of tow theoretical models. Management Science, 35(8), 982-1003.

De L, D. W., \& Fahey, L. (2000). Diagnosing cultural barriers to knowledge management. Academy of Management Executive,14(4), 113-127.

Detert, J. R., \& Edmondson, A. C. (2007). Why employees are afraid to speak. Harvard Business Review, 85(5), 23-25.

Fenwick. R. , Olson. J., (1986), Support for worker participation: attitudes among union and non-union workers, American Sociological Review ,51(4), 505-22.

Fishbein, M.,\& Ajzen, I. (1975). Belief, attitudes, intention and behavior:An introduction to theory and research", Reading, MA: Addison-Wesley.

Gupta ,B, Iyer, L.S. , Aronson, J. E. , (2000) "Knowledge management: practices and challenges", Industrial Management \& Data Systems, 100( 1), 17 - 21.

Grover, V., \& Davenport, T. H. (2001). General perspectives on knowledge management: Fostering a research agenda. Journal of Management Information Systems, 18(1), 5-22.

Hansen, M. T., Nohria, N. , Tierney, T. (1999) "What's your strategy for managing knowledge?" Harvard Business Review, 77( 2), pp 106-116.

Hargadon ,A.B., (1998), Firms as knowledge brokers: lessons in pursuing continuous innovation, California Management Review, 40(3), 209-27.

Hinds, P. J., M. Patterson, and J. Pfeffer. (2008), Bothered by abstraction: The effect of expertise on knowledge transfer and subsequent novice performance. Journal of Applied Psychology, (86(4), 1232-1243.

Holsapple, C., "The inseparability of modern knowledge management and computer-based technology", Journal of Knowledge Management, $r \cdots \Delta, q(1)$ : Pr_or.

Jackson, S. E., C-H. Chuang, E.F. Harden, Y. Jiang, and J.M. Joseph. (2006). Toward developing human resource management systems for knowledge - intensive teamwork. Research in Personnel and Human Resources Management. (25): 27-70.

Kankanhalli ,A, Tan ,B.C.Y. and Wei ,K.K., (2005) ,, Contributing knowledge to electronic repositories: an empirical investigation, MIS Quarterly 29(1) (2005) 113-43.

Ko, D.G., Kirsch, L.J. and W.R. King, (2005), Antecedents of knowledge transfer from consultants to 
clients in enterprise systems implementations, MIS Quarterly, 29(1),59-85.

Kuo,F.Y., Young,M.L.,(2008),Predicting knowledge sharing practices through intention: A test of competing models ,Computers in Human Behavior,24(6), 2697-2722

Liebowitz, J. (2001). Knowledge management and its link to artificial intelligence. Expert Systems With Applications, 20(1), 1-6.

Lin,H.F,(2007), Effects of extrinsic and intrinsic motivation on employee knowledge sharing intentions ,Journal of Information Science, 33(2), 135-149.

Liker ,J.K. , Sindi ,A.A., (1997), User acceptance of expert systems: a test of the theory of reasoned action,Journal of Engineering and Technology Management ,14(2), 147-73.

Luthans, F., (2003),Positive organizational behavior: developing and managing psychological strengths, Academy of Management Executive, 16(1), 57-75.

Morris, M.G.,\& Dillon, A. (1997). How user perceptions influence software use. IEEE Software, 14( 4), 58-65.

Lin, H.F. and Lee, G.G., (2004),Perceptions of senior managers toward knowledge-sharing behaviour, Management Decision, 42(1), 108-25.

Mathieson, K. (1991). Predicting user intentions: Comparing the technology acceptance model with the theory of planne behavior. Information Systems Research, 2(3), 173-191.

Meso, P., Smith, R. (2000). A resource-based view of organizational knowledge management systems. Journal of Knowledge Management, 4(3), 224-234.

Njite,. D. ,. Parsa, H.G , (2005), Structural equation modeling of factors that influence consumer Internet purchase intentions of services, Journal of Services Research, 5(1), 43-60.

Osterloh, M. , Frey, B., , (2000), Motivation, knowledge, transfer, and organizational forms, Organization Science ,11(5), 538-50.

Pikkarainen, T., Pikkarainen, K., Karjaluoto, H., Pahnila, S. (2004). Consumer acceptance of online banking: An extension of the technology acceptance model. Internet Research, 14( 3), 224-235.

Salopek, J.J.(2000), Common Knowledge: How Companies Thrive by Sharing What they Know, Training \& Development,. 54(4), 63-64.

Scarbrough, H., Kinnie, N., "Barriers to the development of team working in Uk firms", Industrial Relations Journal, $r \cdots r, r \varphi(r): 1 r \Delta_{-} \mid r q$.

Schilligo, J.A.(2007), Predictors of Effective Knowledge Management, A Dissertation Submitted to Floria Institue of Technology in Partial Fulfillment of the Requirements for the Degree of Doctor of Philosophy in Industrial / Organizational Psychology, Available at: http://proquest.umi.com/pqdweb.

Scott ,J.W., (2000), Facilitating interorganizational learning with information technology, Journal of Management Information Systems ,17(2), 81-113.

Slocombe, T.E., (1999), Applying the theory of reasoned action to the analysis of an individual's polychronicity, Journal of Managerial Psychology ,14(3), 313-22.

Tohidinia,Z.,V,M.,(2010), Knowledge sharing behaviour and its predictors,Industrial Management \& Data Systems, 110 ( 4), 611-631.

Vallerand, R.J., Deci and Ryan's ,(2000), self-determination theory: a view from the hierarchical model of intrinsic and extrinsic motivation, Psychological Inquiry, 11(4),312-18.

Vallerand, R.J., Pelletier, L.G., Deshaies, P., Cuerrier, J.P.,\& Mongeau, C. (1992). Ajzen and fishbein's theoey of reasoned action as applied to moral behavior: A confirmatory analysis. Journal of Personality and Social Psychology, 62( 1), 98-109. 


\section{Macrothink

Yahya, S. , Goh, W.(2002), Managing Human Resource Toward Achieving Knowledge Management, Journal of Knowledge Management,. 6(5), 457- 468.

Yang, C., and Lian-Chu Chen. 2009. Can organizational knowledge capabilities affect knowledge sharing behavior?. Journal of Information Science, (33)1: 95-109.

Yang, J.T. , Wan, C.S.(2004), Advancing Organizational Effectiveness and Knowledge Management Implementation, Tourism Management, 25(5), 593-601.

Wang, S., and R.A. Noe. 2010. Knowledge sharing: A review and directions for future research. Human Resource Management Review,. (20)2: 115-131.

Wasko, M.M. , Faraj, S., (2005), Why should I share? Examining social capital and knowledge contribution in electronic networks of practice, MIS Quarterly, 29(1) ,35-57. 